\title{
GOAL ORIENTED PROVISION OF DESIGN PRINCIPLES FOR ADDITIVE MANUFACTURING TO SUPPORT CONCEPTUAL DESIGN
}

\author{
Schumacher, Felix (1); Watschke, Hagen (2); Kuschmitz, Sebastian (2); Vietor, Thomas (2) \\ 1: BMW AG; 2: Technische Universität Braunschweig
}

\begin{abstract}
Additive Manufacturing (AM) offers a new degree in design freedom. However, in order to exploit AM's potentials in end-use products a methodical approach and suitable tools especially during conceptual design are needed. This paper presents a methodology for application in industrial practice, which should support the component conception for additively manufactured products. The approach focuses on a benefit-oriented preparation and provision of knowledge. In addition to general design methods for abstraction and promotion of creativity, AM-specific tools are introduced which support the provision of solution principles and process-specific restrictions. A broad applicability of the solution principles is ensured by an expansion of the solution space through abstraction. Consequently, product developers are sensitised to the new design possibilities of AM, on the one hand. On the other hand, they are supported in a holistic exploitation of design potentials in ideation in order to foster innovative solution ideas. Finally, the methodological procedure and the developed tools will be demonstrated in a workshop by using an example from industrial practice of the automotive sector.
\end{abstract}

Keywords: Design for Additive Manufacturing (DfAM), Additive Manufacturing, Creativity, Conceptual design

\section{Contact:}

Schumacher, Felix

BMW AG

Body, Exterior Trim, Pre-Development Programm, Carbon Fiber Strategy

Germany

felix.fs.schumacher@bmw.de

Cite this article: Schumacher, F., Watschke, H., Kuschmitz, S., Vietor, T. (2019) 'Goal Oriented Provision of Design Principles for Additive Manufacturing to Support Conceptual Design', in Proceedings of the 22nd International

Conference on Engineering Design (ICED19), Delft, The Netherlands, 5-8 August 2019. DOI:10.1017/dsi.2019.79 


\section{INTRODUCTION}

With the progress in process and materials technology in additive manufacturing (AM), the possibilities in design are increasing. As a result, the range of applications for additively manufactured end-use products is constantly growing. One major challenge, however, is the conceptual design of components, since design fixations prevent an exploitation of the entire potential of additive manufacturing processes. The majority of product developers and designers lack an awareness of the AM-specific design freedoms ("design potentials"), that those are often only used selectively in component design - e.g. freedom of geometry for topology optimisation to minimise weight.

Besides the geometrical freedom, advantages in respect to a time reduction in the product development process, the functional improvement of components up to the realisation of new functions is possible. In order to a comprehensive exploitation of AM potentials the consideration of abstraction levels is required as well as an analysis of products on assembly level instead of single component level.

In this paper a methodology is presented, which aims at supporting the conceptual design phase for additively manufactured components. The approach addresses both, the benefit-oriented preparation and provision of knowledge as well as its application in form of a workshop concept. In addition to general design methods for abstraction and creativity promotion, the methodology also includes AMspecific tools that support the provision of solution principles and process-specific restrictions. Through a targeted expansion of the solution space (system boundaries), a broad applicability of the solution principles is ensured. In this way the product developer is sensitised to the design possibilities of AM, on the one hand, and, on the other hand, a holistic exhaustion of the design freedom in the ideation phase is forced. Due to that only a selective component optimisation can be prevented. Finally, the applicability of the procedure will be demonstrated using an example from industrial practice.

\section{STATE OF THE ART}

Additive manufacturing offers a new degree of freedom in product development. With the aim to bring together the inherent potentials and restrictions of additive manufacturing processes with the requirements and boundary conditions of possible use cases, design for additive manufacturing (DfAM) approaches have been developed. Examples for tools and methods that can be part of DfAM are solution principles or design rules as well as prefabricated solutions. The application of DfAM approaches depends, among other things, on the time in the product development process, the individual user and his knowledge as well as the respective objective. Especially in recent years, a large number of DfAM approaches have been published. Pradel et al. (2018) have analysed 81 sources and placed them in the context of a framework in which the approaches are assigned to the various phases in the product development process. Particularly frequent in this context are publications that are based on one concrete use case. Basically, all studies distinguished between approaches that either support the application of the potentials of additive manufacturing processes or deal with inherent limitations. Pradel et al. (2018), Laverne et al. (2015) and Kumke et al. (2017) distinguish in this context between opportunistic and restrictive DfAM approaches as well as a combination of both, referred to as combined DfAM approaches. In addition, a distinction can be made between approaches that focus on the application of AM potentials either at component level or independently of existing system boundaries at assembly level. In the context of this paper the exploitation of AM potentials during the conceptual phase of the product development process is focussed.

\subsection{Access to AM specific knowledge in ideation}

As stated in Laverne et al. (2017) especially opportunistic instead of restrictive knowledge is necessary for the product developer during conceptual design phase. On the other hand, not only the lack of opportunistic knowledge is a hindering factor in the course of using AM potentials. Cognitive barriers can lead to restrained creativity. One widely described effect in literature is design fixation. (Richter et al., 2018) It describes the effect that when solutions from preceding projects with similar or even identical tasks are available, those preceding solutions prevent designers from exploring alternative solutions during ideation. Designers' expertise, instructions, design methods, group work as well as timing are influencing factors. Especially in the context of the practical application in 
companies, processual barriers can be a hindering factor, too. An example is the decision concerning the suitable manufacturing process for a component. In respect to the comprehensive use of the potentials of AM it is crucial to start to consider the potentials in early design phases. In contrast to this, established product development processes are oftentimes designed to determine the manufacturing process late in the product development process. In literature general DfAM approaches exist (Kumke et al., 2016). Especially in case of the introduction of AM technologies in companies the use of general DfAM approaches is suitable.

Laverne et al. (2016) introduces a methodical proposal where a Design with X approach is used for the ideation phase followed by a Design for AM approach for the following detailed design. The work mainly addresses the identification of the right time, the right user and the right format for the use of AM knowledge during the ideation phase of the product development. In this course four types of AM knowledge (Text, Artifact, Video and Pictures) are studied. However the access to AM knowledge in the context of a given design problem is not described in this work. In fact the designer has to figure out for himself which AM principles are suitable for the given design problem.

Other publications provide case studies with detailed examples of the use of AM without considering the practicality for other use cases. Examples are publications in respect to topology optimisation (Watts and Hague, 2006) or the consolidation of many parts into one part (Schmelzle et al., 2015). A straightforward transfer of AM potentials demonstrated in case studies to other product categories can oftentimes not be achieved. Therefore, in terms of the application of AM potentials in the industrial practice more detailed guidance for the developer as well as a more goal-oriented provision of solution principles taking into account the specific requirements of a given design problem is crucial. In the course of several projects with companies from different industries the implementation of DfAM approaches in the form of workshops has been proved suitable. Workshops provide a timeframe for the participants in which focused and goal oriented work on one topic, without distraction from day to day business is possible.

\section{RESEARCH QUESTIONS}

Considering the presented preliminary work in resprect to existing DfAM approaches the research questions of this paper are presented in the following.

1. In which form must the conceptual design phase be supported with regard to the application of the potentials of additive manufacturing processes by means of a methodical procedure and tools?

a. Is the presented methodical procedure and the use of the illustrated product models suitable and sufficient goal-oriented for the use in conceptual design?

b. Do the introduced principle cards support the ideation process? Is the illustrated access logic by means of functions sufficient goal-oriented and helpfully? Is the mix of opportunistic and restrictive knowledge helpful?

c. Are the provided additively produced objects suitable with regard to the inspiration and understanding of the potentials of AM in respect to innovative ideation?

2. Is a realistic assessment and consideration of AM potentials (also uncommonly used like 4D printing or multi-material AM) during idea generation possible with the help of the applied procedure and resources. Is the AM-specific component conception facilitated by that?

\section{METHODICAL APPROACH AND TOOLS}

The methodical approach is implemented in a workshop concept that can be divided into three phases (see Figure 1). In order to guide the participants in developing solution ideas by utilising AM-specific design potentials in the course of the workshop, several methodical tools are provided. Figure 2 gives an overview of the three workshop phases by introducing the overall approach and available resources per phase as well as the expected results. 


\begin{tabular}{|c|c|c|c|}
\hline & Approach & Resources & Results \\
\hline Abstraction & $\begin{array}{l}\text { Derivation of functions from } \\
\text { requirements and existing solution }\end{array}$ & $\begin{array}{l}\text { - Existing products } \\
\text { - Experts }\end{array}$ & $\begin{array}{l}\text { - Module Interface Graph } \\
\text { - Function structure }\end{array}$ \\
\hline $\begin{array}{ll} & \text { ideation } \\
\cdot \frac{50}{5} & \\
0 & \end{array}$ & $\begin{array}{l}\text { Identification of pertinent solution } \\
\text { principles for the derived functions }\end{array}$ & $\begin{array}{l}\text { - Function-property-matrix } \\
\text { - Principle cards (front side) } \\
\text { - AM objects }\end{array}$ & $\begin{array}{l}\text { - List of suitable working principles } \\
\text { for a redesign }\end{array}$ \\
\hline 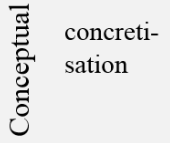 & $\begin{array}{l}\text { Concretisation of solution ideas } \\
\text { considering required functions } \\
\text { and restrictions }\end{array}$ & $\begin{array}{l}\text { - Principle cards (back side) } \\
\text { - Process related capabilities } \\
\text { and restrictions } \\
\text { - AM objects }\end{array}$ & $\begin{array}{l}\text { - Realistic draft of component in } \\
\text { form of sketches considering technical } \\
\text { feasibility and AM's design potentials }\end{array}$ \\
\hline
\end{tabular}

Figure 1: Methodical approach to facilitate utilising AM potentials in conceptual design

\subsection{Abstraction phase}

One of the main goals during abstraction phase is breaking with conventional design. In order to prevent the designer from design fixations an abstract representation of the given use case is necessary. In this context a trade-off between abstraction and concrete, detailed functional representations exists. One possible way for representation is the use of a Module Interface Graph (MIG). Blees et al. (2010) report that MIG represent an efficient tool accepted by industrial partners and suitable for discussion between different departments. Especially in the context of the use of AM design freedom in conceptual design phase, it is crucial to consider potentials independent from department functions (boundaries). The two dimensional abstract visualisation of MIG with the focus on functions helps developers to detach themselves from existing solutions and at the same time supports the way of thinking in abstraction levels. In this contribution, three types of flows are represented within MIG: Flow of information (e.g. sensor data for park distance control), flow of energy (e.g. electrical energy for car lighting) and flow of material or solid (e.g. cleaning water for sensors). These flows are represented in the form of different coloured lines. In order to avoid the limitation of the design engineer in the available solution space there are no strict component or module boundaries represented. Therefore, an application of potentials like part consolidation or functional integration are possible. The functions that have to be fulfilled within the system boundaries are categorised. Consequently, the user is able to access the provided AM knowledge by means of this systematisation (see chapter 4.2). (Simpson et al., 2014)

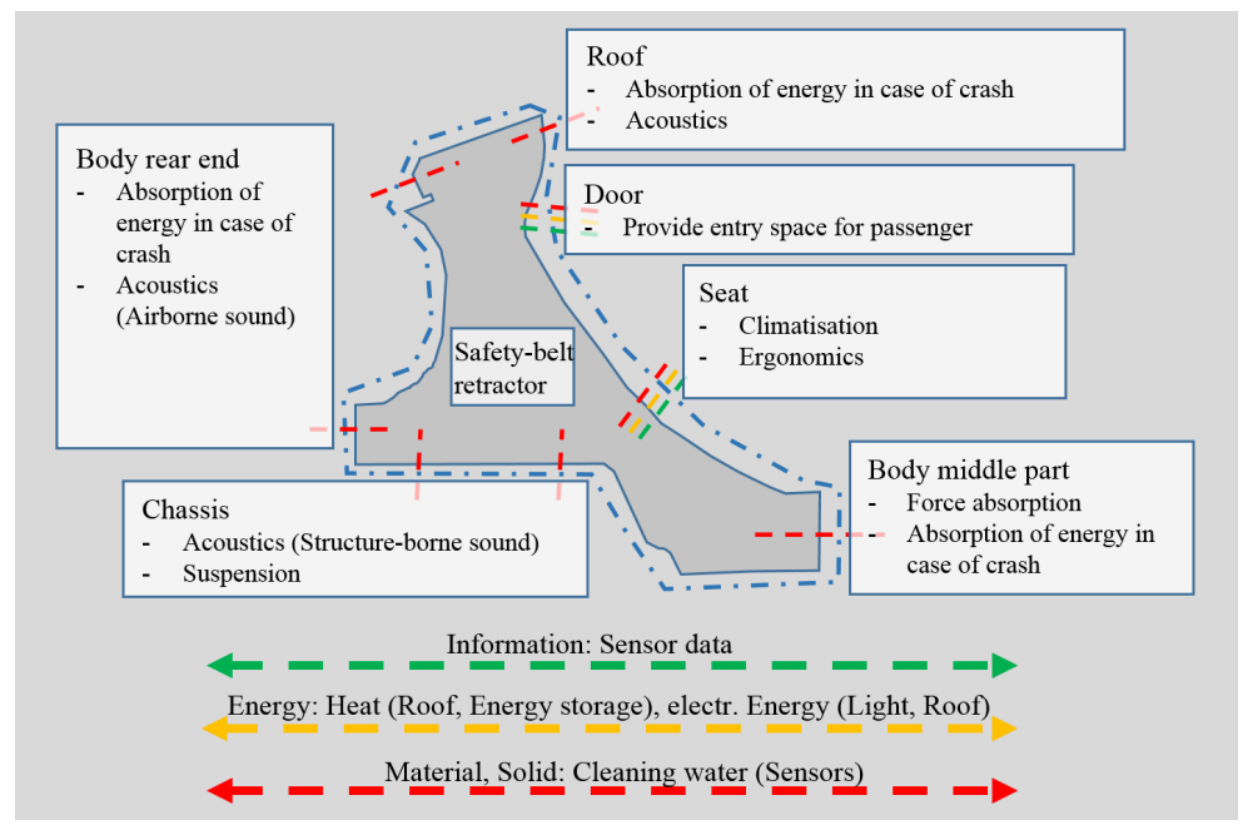

Figure 2: Module Interface Graph of an automobile C-pillar structure 


\subsection{Conceptual design phase}

Based on the reassessment of the problem definition, design fixations should be overcome and AM knowledge can be provided for utilising AM design potentials in redesign. An abstract problem definition allows an access to design principles based on general functions proposed by Roth (2000) and foster an extension of the solution space. Besides a guided access to design principles, Laverne $e t$ al. (2017) emphasise the importance of AM-specific knowledge provision in early design stages. Therefore, a systematic access and so-called principles cards for provision of opportunistic and restrictive knowledge has been developed to support consideration of AM's capabilities in conceptual design stage.

In total, 23 design principles derived by analysing AM use cases and extracting key functions are provided in the workshop. A similar approach for the extraction of design principles from existing products can be found in the contribution of Yilmaz (2010) (see also Ulman (2010)). The focus of this work however lies on the way the design principles are preparated and provided to the designer during the conceptual design phase. Examples for the preparated design principles are the realisation of porous acoustical structures for absorbing noise, the integration of joints and hinges by means of hierarchical structures and elastic materials, as well as customisation by use of individualised logos, assembly instructions or visual and haptic surfaces by combining materials with fluorescent properties or filled with wood. Besides more uncommonly used design capabilities of AM are also considered, for example, function integration by means of multi-material AM and temporally changeable features based on shape memory polymers. Figure 3 shows a systematisation of the identified design principles by general function definitions to allow a guided and function-oriented access to the principles on the basis of product models like MIG or function structure (see section 4.1). The principle on the right side in Figure 3 shows the integration of bearing elements through the use of materials with high abrasion resistance and a low coefficient of friction. The principle cards are accessed by assigning flow definitions to general operations. For example, P04 can be found in the "Energy - Channel" cell.

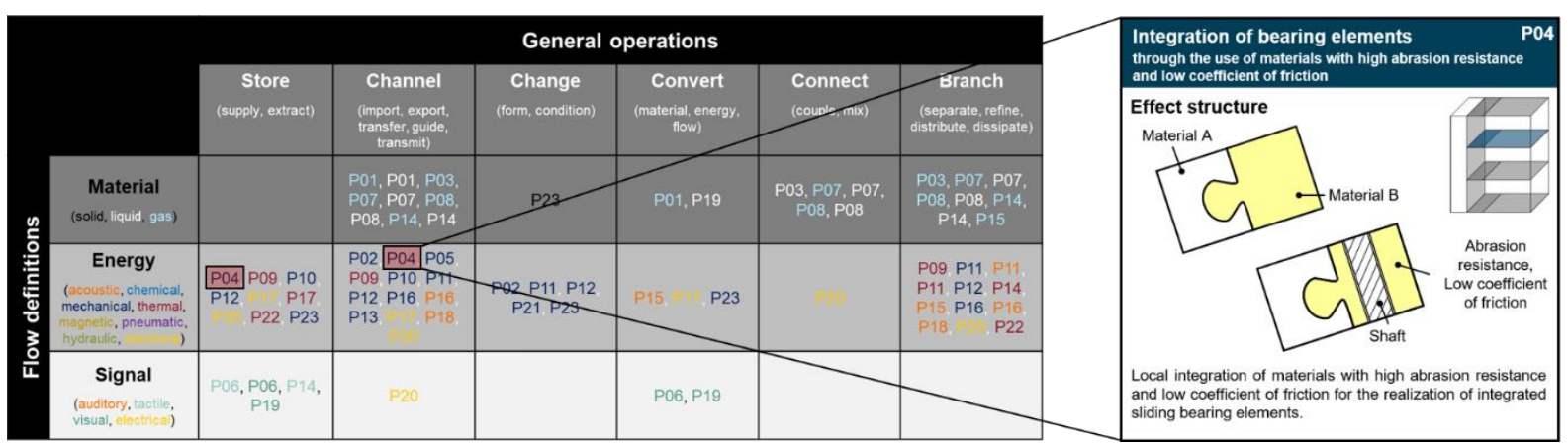

Figure 3: Matrix for systematisation of design principles based on general functions

In order to facilitate the selection of pertinent design principles for the participants of the workshop and supporting the development of solution ideas concerning the design task, specific knowledge must be provided regarding both, AM's design freedom and limitations. Therefore, the principle cards have two sides with different knowledge to support ideation by providing opportunistic knowledge as well as assessment and concretisation of solution ideas, respectively, by offering restrictive knowledge. The layout and content of the principle cards are presented in the following.

\subsubsection{Front side of principle card: getting access and description of solution principle (ideation)}

Figure 4 shows on the left the front side of a principle card. Title, number, and a short description facilitate the access to solution principles and allow a first evaluation of the pertinence of the selected solution principle for the design task. Besides this, positive and negative influenced design goals should help the participants of the workshop to assess the suitability of the solution principle in more detail. Further, to foster a deeper understanding of the working principle, a detailed description and appropriate AM artefacts for inspiration and stimulating creativity are provided. Due to that, the participant is guided by selection of a pertinent solution principle for the specific design task. In addition, additively manufactured objects are provided (see Figure 4 right) to foster inspiration by visualising AM-specific design features and capabilities and help to understand the working principles by interacting. 

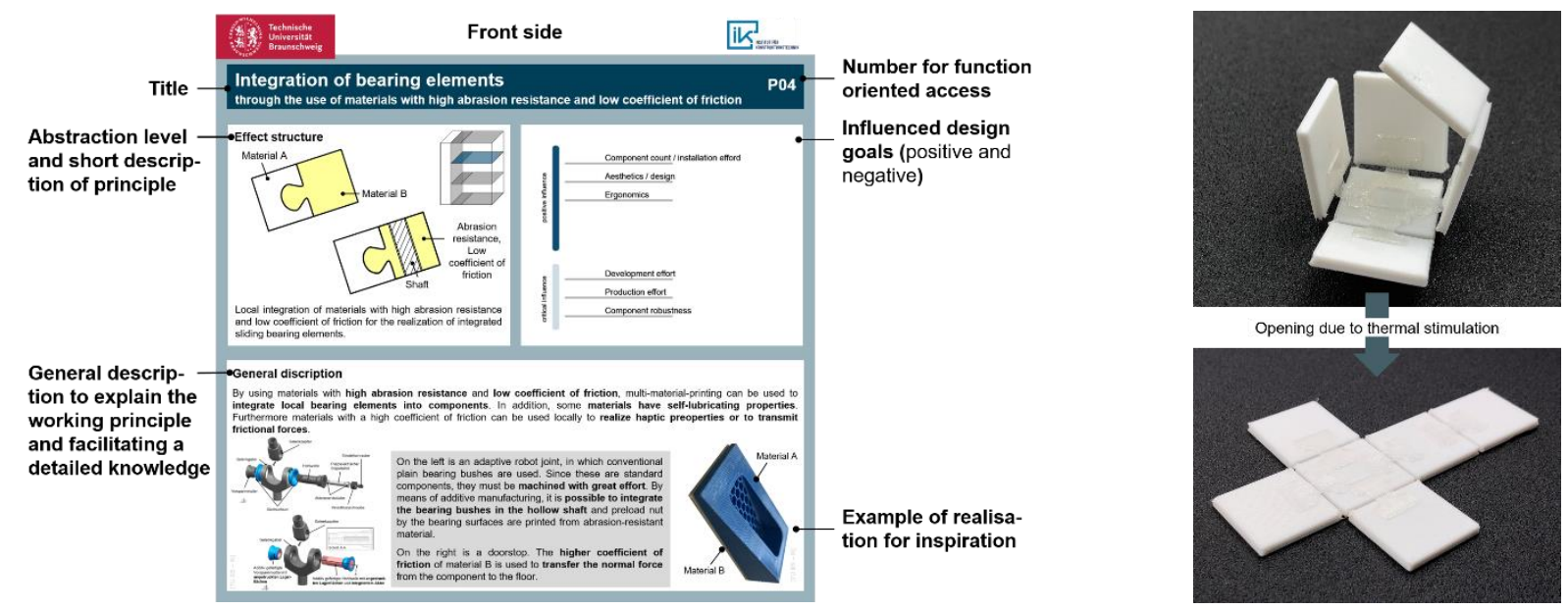

Figure 4: Front side of principle card, exemplarily shown by means of the integration of bearings by utilising multi-material AM and picture of additively manufactured object

\subsubsection{Back side of principle card: principle specific AM capabilities and limitations (concretisation)}

The included information on the back side of the principle cards allow a concretisation and evaluation of the solution ideas by considering both, AM's capabilities and restrictions. In the upper part of Figure 5 (left) design opportunities related to the principle are listed. Besides general levers regarding AM's design freedom (see Kumke et al., 2017), also knowledge about process-specific design parameters, for instance raster angle orientation to influence stiffness, are provided to enhance and exploit design capabilities, respectively. Consequently, the generated solution ideas can be concretised utilising AM's inherent design freedom, especially for an assistance of novice designers in the field of DfAM.

In comparison to that, in the lower part rudimentary knowledge and advises specific to AM's limitations related to the solution principle are presented, for instance, regarding surface roughness depending on built orientation or material compatibility. In consequence, the participants are sensitised to challenges in realisation of the design solution. Further, providing restrictive knowledge about realisable feature sizes and process specific resolution capabilities facilitates a realistic assessment of the solution ideas. Thus, the AM objects offered in the workshop also show limitations like increased surface roughness and defects on the down-skin surface depending in overhang angle and feature size (see Figure 5 right). However, the provided restrictive knowledge is formulated as general as possible that creativity is not restrained, but the technical feasibility of the generated solution ideas is generally considered.
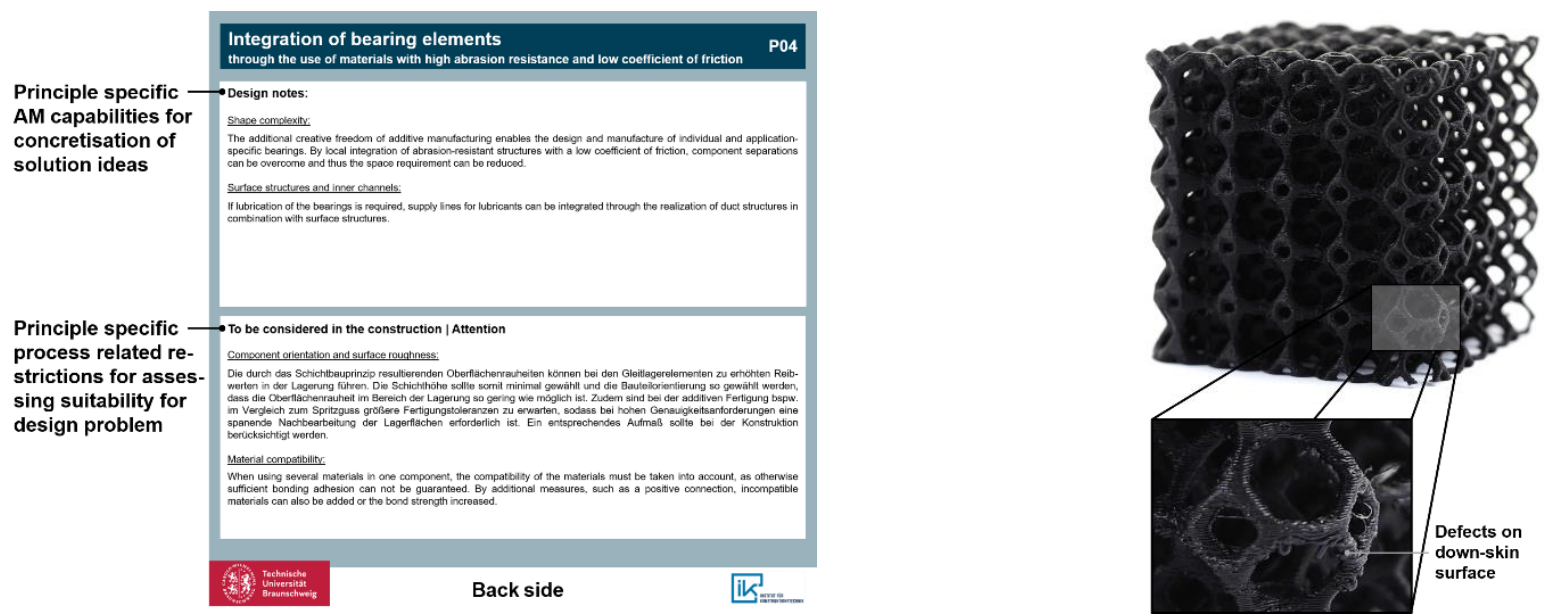

Figure 5: Back side of principle card, exemplarily shown by means of the integration of bearings by utilising multi-material $A M$

Hence, by means of the provided principle cards and AM objects in combination with the guided access to the design principles the redesign and the preparation of sketches are facilitated by 
considering AM's new design potential. Due to the provision of basic knowledge about principle related limitations, the generated solution ideas are more realistic. Since the solution ideas include process-specific capabilities and restrictions, they are a good basis for the embodiment design and detail design, respectively.

\section{APPLICATION OF METHODOLOGY AND TOOLS IN A WORKSHOP}

In the following chapter, the workshop conducted in an industrial environment in the automotive sector is described in more detail. For this reason, the workshop composition, in particular the experiences and qualifications of the participants, but also the application examples are explained. Finally, two results of the workshop are presented briefly. In order to evaluate the suitability of the applied methodology and tools a questionnaire was given to the participants. The results of this evaluation are presented, too.

\subsection{Workshop set-up}

The workshop was conducted at an established car manufacturer with a total of seven participants, who are mainly active in the fields of engineering design, structure simulation and design. All participants have several years of professional experience in the field of vehicle development and can thereby make targeted use of their experience. Overall, the circle of participants has advanced knowledge in the area of vehicle technology, product development and design. The knowledge in the field of AM is present, but not excessive. The workshop is designed for about 3 hours, including two work phases of 70 minutes each.

The C-pillar of an innovative automotive concept for the year 2050 served as an application example in the workshop. As a result, the component has different requirements than would be the case today, because in the year 2050 topics such as autonomous driving are assumed to be state of the art. Especially autonomous driving leads to a change in user demands e.g. comfort, ergonomics and design. Against this background the workshop participants should focus on possibilities that result from additive manufacturing so that the C-pillar can be implemented as innovatively as possible. This can be, for example, both a facilitated production, as well as an increase in functionality. The following section explains the results of the workshop in more detail.

\subsection{Workshop implementation}

The course of the workshop is divided into an introductory part by presenting tools for ideation and concretisation, such as the principle cards (see Figure 1). In addition, the task and the application example are explained. Due to time constraints, the participants are provided with an already prepared Module Interface Graph of the C-pillar (see Figure 2). After completion of the introductory part, the first working phase begins. Within this phase, the participants should generate ideas that integrate new functionalities into the application example with the help of additive manufacturing technologies. For this purpose, the participants have different tools available, such as the principle cards as well as additively manufactured artefacts. The ideation phase is explained in more detail in subsection 4.2.1. In the following concretisation phase, the participants prioritised the developed solution ideas and improved them during the second working phase. For this purpose, the participants should check whether the implementation of the ideas is technically feasible and show what restrictions exist. There are different tools available, such as the back sides of the principle cards or the additively manufactured objects, which can be considered as a reference. The concretisation phase is explained in more detail in chapter 4.2.2. Finally, the developed concepts were presented and discussed.

\subsection{Results}

During the workshop, the participants generated 18 concepts and ideas, which were sketched on idea cards. The focus during the ideation phase was on the generation of ideas, whereby technical feasibility played a subordinate role. During the subsequent working phase (concretisation), the participants should use the backs of the principle cards to check technical feasibility of the developed concepts and, if necessary, adapt them so that manufacturing restrictions are considered. Figure 6 shows two elaborated concepts, which are explained in more detail below. 


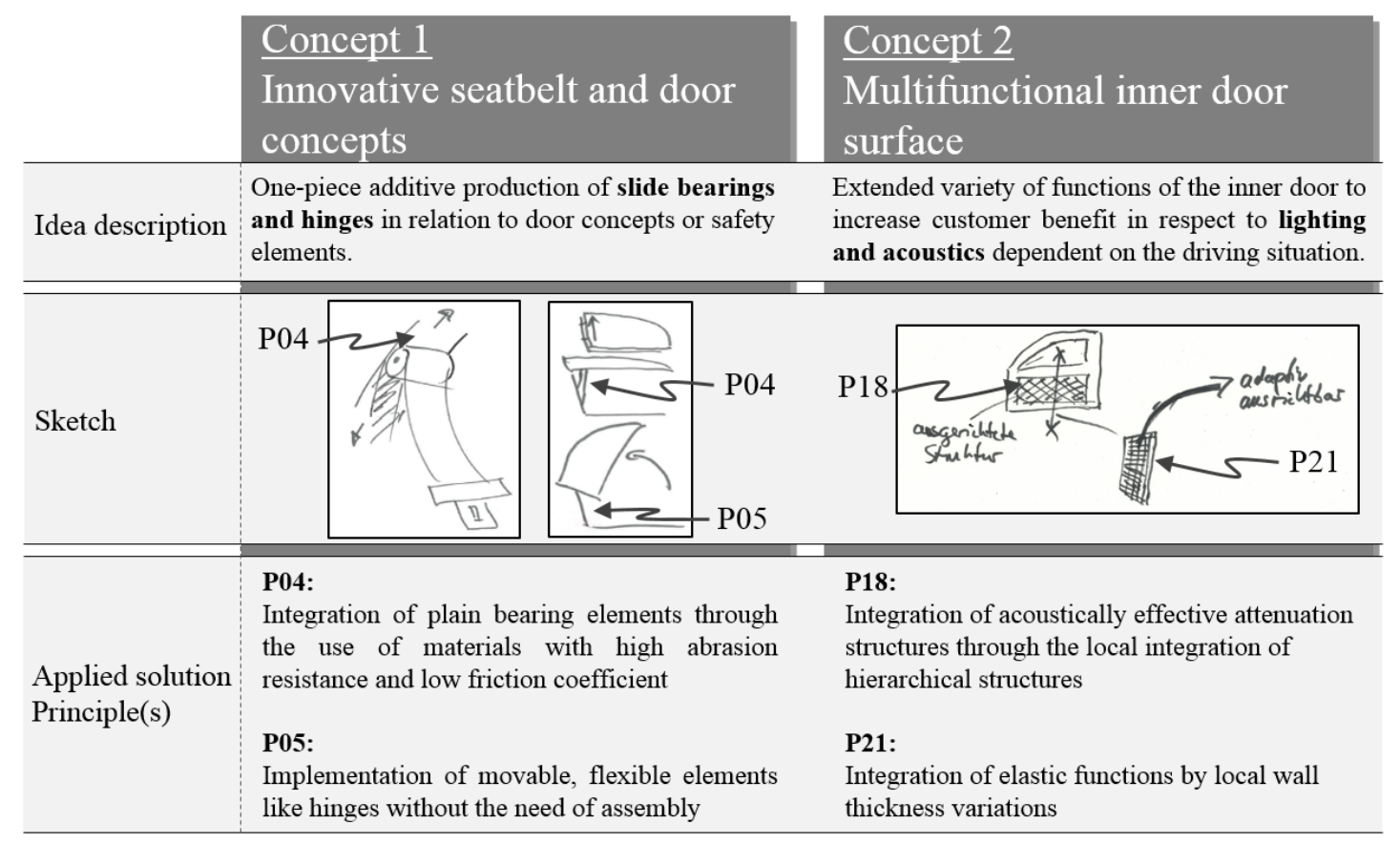

Figure 6: Exemplary presentation of solution ideas from the ideation phase

As part of the workshop, a variety of concepts has emerged that increase both, the functionality of individual components as well as the functionality of the entire automobile. Two of these concepts are briefly elaborated on below.

In the case of autonomous driving it can be assumed that passengers want to be able to get into a lying position. This leads to the requirement that future concepts have to provide solutions for this use case also considering safety aspects. Against this background the first concept describes an adjustable seatbelt that changes its position in respect to the position of the passenger and is implemented in the C-pillar structure (see Figure 6). Position changes of the passenger as well as the seatbelt could be integrated into the C-pillar, giving passengers as much freedom as possible in terms of ergonomics and comfort. Additionally the concept describes the integration of the door hinges in the C-pillar. It is assumed that the B-pillar is not present, so the doors have to be fixed elsewhere. For this application, different options are available that could be integrated into the C-pillar using AM. These concepts can be realized with the AM principles "Integration of plain bearing elements through the use of materials with high abrasion resistance and low friction coefficient" (P04) and "Implementation of moveable, flexible elements like hinges without the need of assembly" (P05). The second concept describes a way to increase the functionality of the inner door surface. By using different potentials of the additive manufacturing processes ("Integration of acoustically effective attenuation structures through the local integration of hierarchical structures" (P18), "Integration of elastic functions by local wall thickness variations" (P21)), functional structures such as acoustic filters or elastic functions can be integrated. In this way, an adaptable lighting of the passenger compartment can be realized and at the same time the absorption of unwanted airborne sound is realised. This concept can also be applied on the Cpillar, but was developed as part of the workshop for the inner door surface.

The evaluation of the workshop was carried out by means of a questionnaire, where, among other things, the procedure, the tools and the realised ideas should be assessed. The evaluation showed that the participants regarded the procedure of the workshop as positive. Five out of seven participants agreed that the principle cards greatly facilitate the generation of ideas. All participants have mentioned especially the methodical tools positively, because innovative working principles are taught, for example, by means of the principle cards. In addition, the AM objects are a suitable way to show the existing potentials through AM and to experience them for yourself. One participant commented negatively that focusing on the C-pillar was a limitation and that ideas for the vehicle as a whole should be developed. This procedure could be tested in further workshops. Overall, it can be stated that the methodical aids (principle cards, AM components, etc.) represent a good opportunity to promote the idea generation of the users. The workshop concept is therefore considered to be well suited for the support of the conceptual phase during product development process. 


\section{CONCLUSION AND FUTURE RESEARCH}

In this paper, previous literature on DfAM approaches is reviewed. In this context limitations especially in respect to ideation phase exist. In order to exploit AM potentials during product development a goal oriented access to opportunistic as well as restrictive knowledge for product developer is needed. Additionally, the abstract representation of use cases is crucial in order to foster designers creativity and at the same time avoid design fixation. Although AM offers a new geometrical freedom in design, restrictions resulting from the production process in the form of for example design guidelines have to be followed during the design process. Hence the consideration of opportunistic as well as restrictive knowledge also during conceptual design phase is crucial.

Based on the derived requirements a methodical approach for a workshop during conceptual phase has been proposed. First, in abstraction phase, the considered use case is represented in an abstract way with the help of a Module Interface Graph. By that, the trade of between abstract and a concrete, detailed functional representations can be resolved so that creativity is supported and design fixation avoided. In the following ideation phase an access logic to AM potentials has been introduced. By the help of a distinction between main functions and three types of flow, the designer is able to access so called principle cards. The core advantages of the principle cards are the provision of suitable opportunistic as well as restrictive AM knowledge represented with facilitated accessibility at the right time during product development process. In addition, additively manufactured artefacts for the physical demonstration of the AM principle cards are provided. The applicability of the approach and the tools is shown in a workshop conducted in a car manufacturing company.

Nonetheless an extensive validation of the described methodical approach respective the proposed tools cannot be realised on the bases on one workshop in this paper. However, the introduced tools like the principle cards have been used in industrial practice and proved themselves useful, for example, in the context of creative assignments.

Future research should focus on the further validation of the proposed approach and tools in industrial practice as well as in academic environments for design method education. Especially the concurrent provision of opportunistic and restrictive knowledge during conceptual design phase should be elaborated further. In the current approach concepts are developed that in the following embodiment phase of the product development process have to be finalised in further detail. Against this background it can be useful to consider crucial boundary conditions that are important for the serial production already in the course of ideation phase.

\section{REFERENCES}

Blees, C., Kipp, T., Beckmann, G., Krause, D. (2010), “Development of Modular Product Families: Integration of Design for Variety and Modularization." Nord Design 2010, (DS, 61), pp. 159-170.

Ehrlenspiel, K., Meerkamm, H. (2013), Integrierte Produktentwicklung. Denkabläufe, Methodeneinsatz, Zusammenarbeit., Hanser, München. http://doi.org/10.3139/9783446436275.

Kumke, M., Watschke, H., Hartogh, P., Bavendiek, A.-K., Vietor, T. (2017), "Methods and tools for identifying and leveraging additive manufacturing design potentials.", International Journal on Interactive Design and Manufacturing, Vol. 21 No. 6, p. 662. http://doi.org/10.1007/s12008-017-0399-7.

Laverne, F., Frédéric, S., Gianluca, D’Antonio, Le Marc, C. (2017), "Enriching design with X through tailored additive manufacturing knowledge. A methodological proposal", International Journal on Interactive Design and Manufacturing, Vol. 11 No. 2, pp. 279-288. http://doi.org/10.1007/s12008-016-0314-7.

Mattmann, I. (2017), Modellintegrierte Produkt- und Prozessentwicklung, Springer Fachmedien, Wiesbaden. http://doi.org/10.1007/978-3-658-19409-3.

Pahl, G., Beitz, W., Feldhusen, J., Grote, K.-H. (2007), Engineering Design, Springer London, London.

Ponn, J. and Lindemann, U. (2011), Konzeptentwicklung und Gestaltung technischer Produkte, Springer, Berlin, Heidelberg.

Pradel, P., Zhu, Z., Bibb, R., Moultrie, J. (2018), “A framework for mapping design for additive manufacturing knowledge for industrial and product design”, Journal of Engineering Design, Vol. 57, pp. 1-36. http://doi.org/10.1080/09544828.2018.1483011.

Richter, T., Watschke, H., Schumacher, F. (2018), "Exploitation of potentials of additive manufacturing in ideation workshops", International Conference on Design Creativity (ICDC 2018), Bath, pp. 1-8.

Roth, K. (2000), Konstruieren mit Konstruktionskatalogen Springer, Berlin Heidelberg. http://doi.org/10.1007/978-3-642-17466-7. 
Richter, T., Watschke, H., Inkermann, D., Vietor, T. (2016), "Produktarchitekturgestaltung unter Berücksichtigung additiver Fertigungsverfahren.”, Entwerfen Entwickeln Erleben 2016 - Beitrage zur virtuellen Produktentwicklung und Konstruktionstechnik, Dresden, pp. 375-392.

Rodrigue, H., Rivette, M. (2010), “An Assembly-Level Design for Additive Manufacturing Methodology”, Proceedings of IDMME - Virtual Concept, Bordeaux.

Schmelzle, J., Kline, E.V., Dickman, C. J., Reutzel, E.W., Jones, G., Simpson, T.W. (2015), “(Re)Designing for Part Consolidation. Understanding the Challenges of Metal Additive Manufacturing." Journal of Mechanical Design, Vol. 137 No. 11, S. 111404. http://doi.org/10.1115/1.4031156.

Schumacher, F., Richter, T., Watschke, H. (2017), "Ein Rahmenwerk zur Wissensbereitstellung für die Nutzung von Potentialen additiver Fertigung in der Produktentwicklung", Kolloquium Konstruktionstechnik KT 2017, Duisburg-Essen, pp. 131-140.

Simpson, T.W., Jiao, J., Siddique, Z., Hölttä-Otto, K. (2014), Advances in Product Family and Product Platform Design. Springer New York, New York, NY.

Ullman, D.G. (2010), The mechanical design process, McGraw-Hill Professional, New York, ISBN-10: 0072975741.

Watts, D.M. and Hague, R.J. (2006), "Exploiting the design freedom of RM”, Solid Freeform Fabrication Symposium, Texas, pp. 656-667.

Yilmaz, S. and Seifert, C.M. (2010), "Cognitive Heuristics in Design Ideation”, Proceedings of 11th International Design Conference, May 17-20 2010, Dubrovnik, Croatia. 